\title{
Plasma-stimulated medium kills TRAIL-resistant human malignant cells by promoting caspase-independent cell death via membrane potential and calcium dynamics modulation
}

\author{
TOMOHIKO TOKUNAGA ${ }^{1}$, TAKASHI ANDO ${ }^{2}$, MIKI SUZUKI-KARASAKI ${ }^{3,4}$, TOMOHISA ITO $^{4}$, \\ ASUKA ONOE-TAKAHASHI ${ }^{5}$, TOYOKO OCHIAI ${ }^{5}$, MASAYOSHI SOMA ${ }^{1}$ and YOSHIHIRO SUZUKI-KARASAKI ${ }^{3,6}$ \\ ${ }^{1}$ Division of General Medicine, Nihon University School of Medicine, Tokyo 173-8610; ${ }^{2}$ Department of Orthopedic Surgery, \\ Yamanashi University School of Medicine, Chuo, Yamanashi 409-3898; ${ }^{3}$ Plasma ChemiBio Laboratory, Nasushiobara, \\ Tochigi 329-2813; ${ }^{4}$ Department of Orthopedic Surgery, Nihon University School of Medicine, Tokyo 173-8610; \\ ${ }^{5}$ Department of Dermatology, Nihon University Hospital, Tokyo 101-8309; ${ }^{6}$ Division of Physiology, \\ Department of Biomedical Sciences, Nihon University School of Medicine, Tokyo 173-8610, Japan
}

Received November 2, 2017; Accepted December 28, 2017

DOI: $10.3892 /$ ijo.2018.4251

\begin{abstract}
Tumor necrosis factor-related apoptosis-inducing ligand (TRAIL) and cold plasma-stimulated medium (PSM) have been shown to exhibit tumor-selective cytotoxicity and have emerged as promising new tools for cancer treatment. However, to date, at least to the best of our knowledge, no data are available as to which substance is more potent in killing cancer cells. Thus, in this study, we systematically compared their abilities to kill human malignant cells from different origins. We found that PSM dose-dependently killed TRAILresistant melanoma, osteosarcoma and neuroblastoma cells. Moreover, PSM had little cytotoxicity toward osteoblasts. PSM was more potent than TRAIL in inducing caspase-3/7 activation, mitochondrial network aberration and caspaseindependent cell death. We also found that PSM was more potent in inducing plasma membrane depolarization (PMD) and disrupting endoplasmic-mitochondrial $\mathrm{Ca}^{2+}$ homeostasis. Moreover, persistent PMD was caused by different membranedepolarizing agents; the use of the anti-type II diabetes drug, glibenclamide, alone caused mitochondrial fragmentation and enhanced TRAIL-induced $\mathrm{Ca}^{2+}$ modulation, mitochondrial network abnormalities and caspase-independent cell killing. These results demonstrate that PSM has a therapeutic advantage over TRAIL owing to its greater capacity to evoke caspase-independent cell death via mitochondrial network aberration by disrupting membrane potential and $\mathrm{Ca}^{2+}$
\end{abstract}

Correspondence to: Dr Yoshihiro Suzuki-Karasaki, Plasma ChemiBio Laboratory, 398 Takaatsu, Nasushiobara, Tochigi 329-2813, Japan

E-mail: suzuki.pcbl@gmail.com

Key words: TRAIL, cold plasma-stimulated medium, calcium, non-apoptotic cell death, mitochondrial dynamics homeostasis. These findings may provide a strong rationale for developing PSM as a novel approach for the treatment of TRAIL-resistant malignant cells.

\section{Introduction}

Despite the remarkable progress made in cancer biology and technologies for cancer treatment over the past 50 years, malignant neoplasms remain highly threatening diseases for humans. Malignant neoplasms at the initial stage are curable; however, once they have progressed, they become invasive, metastatic and highly resistant to multi-disciplinary treatments, including chemo-, radio- and immunotherapy. Malignant melanoma and osteosarcoma are representatives of malignant tumors that are highly resistant to multiple anticancer drugs (1-4). Tumor necrosis factor-related apoptosis-inducing ligand (Apo2L/TRAIL), a member of the tumor necrosis factor superfamily, is a promising cancer-selective anticancer drug, since it exhibits potent cytotoxicity toward various cancer cell types with minimal cytotoxicity toward non-transformed cells (5-8). TRAIL triggers the extrinsic and intrinsic apoptotic pathways by binding to two death receptors (DRs), TRAIL receptor (TRAIL-R)1/DR4 and TRAIL-R2/ DR5 $(9,10)$. Disconcertingly, however, current clinical trials have revealed that several cancer cell types, including melanoma and osteosarcoma are resistant to TRAIL, despite expressing DRs (11-15). In addition to their inherent resistance, the acquired resistance to the drug dampens effective TRAIL treatment.

Recently, non-thermal (cold) atmospheric plasma (CAP) has emerged as a novel promising anticancer tool, since it has potent antitumor activity. CAP irradiation inhibits cell proliferation, migration and invasion, and triggers different cell death modalities, including apoptosis, necrosis and autophagy in vitro in various cancer cell lines and primary cancerous cells and tissues (16-23). CAP irradiation also reduces the growth of xenografted tumors in vivo (24). Moreover, CAP irradiation is tumor-selective under the optimal conditions $(16,17,20)$. 
However, the outreach of CAP is very limited so that its primary targets may be limited to cancerous surface tissues. More recently, various types of plasma-stimulated medium (PSM) have been generated from culture medium, buffers and water. PSM has emerged as an alternative tool for cancer treatment, since similar to direct CAP irradiation, it exhibits potent cytotoxicity toward various malignant cells, such as glioblastoma, ovarian, gastric and pancreatic cancers, while causing minimal damage to normal cell counterparts under optimal conditions (25-29). PSM seems to affect a wider range of cancers than CAP irradiation, as it can be readily administered systematically or locally to deep tissues.

$\mathrm{Ca}^{2+}$ is an essential intracellular second messenger whose level is tightly regulated. The finely and spatiotemporal tuning of $\mathrm{Ca}^{2+}$ leads to short and synchronized $\mathrm{Ca}^{2+}$ waves, which are primarily essential for energy production, cell function and survival (30). However, a significant and persistent increase in $\mathrm{Ca}^{2+}$ is a master cause of cell death. An excess rise in the mitochondrial $\mathrm{Ca}^{2+}$ concentration $\left(\left[\mathrm{Ca}^{2+}\right]_{\text {mit }}\right)$, so-called mitochondrial $\mathrm{Ca}^{2+}$ overload, can cause both necrosis and apoptosis; this results in the increased permeability of the inner mitochondrial membrane, mitochondrial permeability transition (MPT). MPT, in turn, leads to a rapid collapse of mitochondrial membrane potential, the loss of ATP and the osmotic rupture of the outer mitochondrial membrane. Ultimately, the loss of ATP and the fall of the mitochondrial integrity lead to necrosis $(30,31)$. In addition, the rupture of the outer mitochondrial membrane can result in the release of different pro-apoptotic proteins, such as cytochrome $c$ and apoptosisinducing factor $(32,33)$, thereby leading to apoptosis. Recent evidence suggests that $\mathrm{Ca}^{2+}$ also plays a regulatory role in other cell death modalities, such as autophagy and anoikis (34). Furthermore, different cancer cell types exhibit tumor-specific traits in $\mathrm{Ca}^{2+}$ dynamics, which contribute to tumorigenesis, malignant phenotypes, drug resistance, increased proliferation, and evasion from apoptosis and survival (35). Thus, $\mathrm{Ca}^{2+}$ is emerging as a novel target for cancer treatment $(36,37)$.

Mitochondria are highly dynamic organelles with a reticular network organization that is regulated by the delicate balance between the fission and fusion of the mitochondrial membrane. The mitochondrial network is critical for cell function and apoptosis $(38,39)$, since a defect in either fission or fusion causes severe mitochondrial and cellular dysfunctions. Mitochondrial fission helps to eliminate damaged mitochondria through mitophagy (40). Accordingly, the disruption of mitochondrial fission leads to an extensively interconnected and collapsed mitochondrial network and defects in mitochondrial quality control. Moreover, mitochondrial fusion facilitates the exchange of mitochondrial DNA and metabolites required for mitochondrial function. Consequently, defects in mitochondrial fusion lead to mitochondrial fragmentation and the loss of mitochondrial DNA, reduced growth, decreased mitochondrial membrane potential (also known as $\Delta \Psi_{\mathrm{m}}$ ) and defective respiration $(41,42)$. A series of our earlier studies have revealed the importance of the mitochondrial network dynamics in melanoma and osteosarcoma cells. We have previously demonstrated that cell killing by TRAIL or PSM, as well as sensitization to either insult is preceded by mitochondrial network alterations, such as excessive mitochondrial fragmentation and clustering or hyperfusion (43-45). Moreover, we found several critical regulators of mitochondrial morphology. One key regulator is plasma membrane depolarization (PMD). Persistent PMD is essential for the progression of mitochondrial fragmentation and clustering (46). The other regulator is $\mathrm{Ca}^{2+}$ since mitochondria $\mathrm{Ca}^{2+}\left(\left[\mathrm{Ca}^{2+}\right]_{\text {mit }}\right)$ overload leads to mitochondrial fragmentation, while $\left[\mathrm{Ca}^{2+}\right]_{\text {mit }}$ depletion results in mitochondrial hyperfusion $(46,47)$.

TRAIL and CAP/PSM share several biochemical and biological properties, including the production of, and regulation by reactive oxygen/nitrogen species (RONS), the induction of apoptosis via the intrinsic pathway, and high tumor-selective cytotoxicity $(19,21,45)$. The advantages of PSM over TRAIL may provide a significant driving force in its development as a novel tool for cancer treatment. However, at present, it is unclear as to whether PSM is more efficient than TRAIL, since, at least to the best of our knowledge, there is no available literature comparing their antitumor activity under given conditions between them. Therefore, in the present study, we systematically compared their ability to kill cancerous cells, disrupt the mitochondrial network dynamics, and to modulate pro-death events between TRAIL and PSM. We found that PSM evoked caspase-independent cell death and efficiently killed different cancer cell types that were highly tolerant to TRAIL. We also found that PSM had a greater capacity to evoke mitochondrial network aberration, $\mathrm{PMD}$ and $\mathrm{Ca}^{2+}$ dynamics dyshomeostasis.

\section{Materials and methods}

Materials. Soluble recombinant human TRAIL was obtained from Enzo Life Sciences (San Diego, CA, USA). The general caspase inhibitor, z-VAD-FMK, and caspase-3/7-specific inhibitor, z-DEVD-FMK, were purchased from Merck Japan (Tokyo, Japan). Glibenclamide, FCCP, antimycin A and U37883A were from Sigma-Aldrich (St. Louis, MO, USA). Potassium chloride $(\mathrm{KCl})$ was obtained from Wako Pure Chemicals (Osaka, Japan). Insoluble reagents (z-VAD-FMK, z-DEVD-FMK, glibenclamide, FCCP, antimycin A and U37883A) were dissolved in dimethyl sulfoxide (DMSO) and diluted with high glucose-containing Dulbecco's modified Eagle's medium (DMEM; Sigma-Aldrich) supplemented with $10 \%$ fetal bovine serum (FBS; Sigma-Aldrich) or Hank's balanced salt solution (HBSS) ( $\mathrm{pH}$ 7.4) to a final concentration of $<0.1 \%$ prior to use. The manganese-porphyrin superoxide dismutase mimetic MnTBaP (Enzo Life Sciences) were dissolved in $1 \mathrm{mM} \mathrm{NaOH}(\mathrm{pH}$ 8.0) and added HBSS to lower $\mathrm{pH} 7.4$.

Cell culture. The following cell lines were used in the present study: Human malignant melanoma cells (A2058, cell number IFO50276), human osteosarcoma cells (MG63, cell number IFO50108) (both from the Health Science Research Resource Bank, Osaka, Japan), human neuroblastoma cells (NB-1, cell number RCB1953 and SK-N-SH, cell number RCB0426), osteosarcoma cells (143B, cell number RCB0701; SAOS-2, cell number RCB0428; and HOS, cell number RCB0992), murine osteosarcoma cells (LM8, cell number RCB1450) and murine osteoblasts (MC3T3-E1, cell number RCB1126) (all from the Riken BioResource Center, Tukuba, Japan). It should be noted that the 143B cell line is identical to the osteosarcoma HTK 
cell line (http://web.expasy.org/cellosaurus/CVCL_2270). However, as the HTK cell line is also an osteosarcoma cell line, it was deemed that this would not affect the outcome of this study. In addition, human malignant melanoma cells (A375, ATCC ${ }^{\circledast}$ CRL 1619 ${ }^{\mathrm{TM}}$ ) and immortalized osteoblast cells (hFOB1.19, ATCC ${ }^{\circledR}$ CRL $11372^{\mathrm{TM}}$ ) were obtained from the American Type Culture Collection (ATCC, Manassas, VA, USA) and the murine osteosarcoma K7M3 cells, originally derived from a primary osteosarcoma in a BALB/c mouse were generously provided by Dr Eugenie Kleinerman (Department of Pediatrics, University of Texas MD Anderson Cancer Center, Houston, TX, USA). Human dermal fibroblasts (HDFs) from the facial dermis were obtained from Cell Applications (San Diego, CA, USA). All cells, apart from the hFOB were cultured in 10\% FBS/DMEM and streptomycin and penicillin $(5000 \mathrm{units} / \mathrm{ml})$ and streptomycin $(5000 \mu \mathrm{g} / \mathrm{ml})$ (Pen-Strep; Thermo Fisher Scientific Japan, Tokyo, Japan) in a 95\% air $/ 5 \% \mathrm{CO}_{2}$ humidified atmosphere. The $\mathrm{hFOB}$ cell line was cultured according to the ATCC protocol. The cells were harvested by incubation with $0.25 \%$ trypsin-EDTA (Thermo Fisher Scientific Japan) for $5 \mathrm{~min}$ at $37^{\circ} \mathrm{C}$.

PSM preparation. CAP was generated using an originallydeveloped low-frequency plasma jet device equipped with an asymmetrical dielectric barrier discharge, as previously described (45). The typical frequency was $20 \mathrm{kHz}$, with a peak voltage of $8 \mathrm{kV}$, a current of $20 \mathrm{~mA}$ and helium flow rate of $300 \mathrm{ml} / \mathrm{min}$. PSM was prepared by irradiating $1 \mathrm{ml}$ of DMEM with CAP for 5 min once. The original PSM was diluted to a final concentration of $12.5-50 \%$ with $10 \%$ FBS/DMEM (for cell experiments) or HBSS (for biochemical experiments) and indicated as PSM (12.5-50\%).

Cell viability assay. Cell viability was measured by WST-8 assay, a colorimetric assay based on the formation of a watersoluble formazan product assay using the Cell Counting Reagent SF (Nacalai Tesque, Kyoto, Japan) as previously described (46). The cells were seeded at a density of $2 \times 10^{3}$ cells/well in 96-well plates (Corning, New York, NY, USA) and incubated for 24 or $72 \mathrm{~h}$ with $100 \mathrm{ng} / \mathrm{ml}$ TRAIL and PSM (3.1, 6.3, 12.5 and 25.50\%) alone or in combination prior to the addition of $10 \mu \mathrm{l}$ of cell counting reagent SF and further incubation for $1 \mathrm{~h}$. The absorbances were measured at $450 \mathrm{~nm}$ using an ARVO MX microplate reader (Perkin-Elmer, Waltham, MA, USA).

Caspase-3/7 activation, membrane integrity and cell death assay. Caspase-3/7 activation, membrane integrity and cell death were simultaneously measured using a Muse ${ }^{\mathrm{TM}} \mathrm{Cell}$ Analyzer (Merck Millipore, Darmstadt, Germany) with the Muse $^{\mathrm{TM}}$ Caspase-3/7 kit as previously described (46). Briefly, the cells $\left(1 \times 10^{5} / \mathrm{ml}\right)$ in 24 -well plates were treated with the agents to be tested $100 \mathrm{ng} / \mathrm{ml}$ TRAIL and PSM (25 and 100\%) alone or in combination in the absence or presence of $10 \mu \mathrm{M}$ Z-VAD-FMK or $30 \mu \mathrm{M}$ MnTBaP for $24 \mathrm{~h}$ in $10 \% \mathrm{FBS} / \mathrm{DMEM}$ at $37^{\circ} \mathrm{C}$ and then stained with a novel Caspase-3/7 reagent NucView $^{\mathrm{TM}}$ and 7-amino-actinomycin D (7-AAD). 7-AAD is a dead cell marker that is excluded from healthy and early apoptotic cells, while it permeates late apoptotic and dead cells. Accordingly, 4 cell populations can be distinguished by this method: Live cells, caspase/7-AAD; early apoptotic cells, caspase $^{+} / 7-\mathrm{AAD}^{-}$; late apoptotic/dead cells, caspase ${ }^{+} / 7-\mathrm{AAD}^{+}$; necrotic cells, caspase-/7-AAD .

Live-cell mitochondrial network imaging. The mitochondrial network was analyzed as previously described (44). Briefly, cells in FBS/DMEM (3×10/well) adherent on an 8-well chambered coverslips were treated with the agents to be tested $100 \mathrm{ng} / \mathrm{ml}$ TRAIL and PSM (25\%) alone or in combination in the absence or presence of $10 \mu \mathrm{M}$ Z-VAD-FMK or $30 \mu \mathrm{M} \mathrm{MnTBaP}$ for $24 \mathrm{~h}$ at $37^{\circ} \mathrm{C}$ in a $5 \% \mathrm{CO}_{2}$ incubator. After removing the medium by aspiration, the cells were washed with fresh FBS/DMEM and stained with $20 \mathrm{nM}$ MitoTracker Red CMXRos (Thermo Fisher Scientific Japan) and $1 \mu \mathrm{g} / \mathrm{ml}$ Hoechst 33342 (Dojindo Laboratories, Kumamoto, Kumamoto, Japan) for $1 \mathrm{~h}$ at $37^{\circ} \mathrm{C}$ in the dark in a $5 \% \mathrm{CO}_{2}$ incubator. The cells were then washed with and immersed in FluoroBrite ${ }^{\mathrm{TM}}$ DMEM (Thermo Fisher Scientific Japan). Images were obtained using a BZ X-700 Fluorescence Microscope (Keyence, Osaka, Japan) equipped with a X100, 1.40 n.a. UPlanSApo Super-Apochromat, coverslip-corrected oil objective (Olympus, Tokyo, Japan). Images were analyzed using BZ-H3A application software (Keyence) and free NIH ImageJ software (NIH, Bethesda, MD, USA).

Measurument of PMD. PMD was measured using an anionic bis-oxonol voltage-sensitive dye $\mathrm{DiBAC}_{4}(3)$. Briefly, the cells $\left(1 \times 10^{6}\right.$ cells $\left./ \mathrm{ml}\right)$ suspended in HBSS were incubated with $5 \mu \mathrm{M} \mathrm{DiBAC}_{4}$ (3) (Dojindo Laboratories) for $40 \mathrm{~min}$ at $37^{\circ} \mathrm{C}$ for loading. The cells were washed, resuspended in HBSS, and measured for their fluorescence for 1, 3,5 and $10 \mathrm{~min}$ using a microplate fluorescence reader (Fluoroskan Ascent; Thermo Fisher Scientific Japan) with excitation and emission at 485 and $538 \mathrm{~nm}$. The data are expressed as the fluorescence intensity normalized (per $1 \times 10^{6}$ cells).

Measurment of $\mathrm{Ca}^{2+}$ concentrations. Changes in the cytosolic $\mathrm{Ca}^{2+}\left(\left[\mathrm{Ca}^{2+}\right]_{\text {cyt }}\right)$ and $\left[\mathrm{Ca}^{2+}\right]_{\text {mit }}$ levels were measured using Fluo 4-AM and rhod 2-AM (Dojindo Laboratories), respectively as previously described $(46,47)$. For the improvement of mitochondrial localization of rhod 2-AM, it was reduced to the colorless, non-fluorescent dihydrorhod 2-AM by sodium borohydride, according to the manufacturer's instructions. The cells were loaded with $4 \mu \mathrm{M}$ each of Fluo $4-\mathrm{AM}$ or dihydrorhod 2-AM for $40 \mathrm{~min}$ at $37^{\circ} \mathrm{C}$, washed with HBSS. Subsequently, the cells $\left(1 \times 10^{6} / \mathrm{ml}\right)$ were resuspended in HBSS in 96-well plates. The cells were then manually supplemented with the agents to be tested PSM (12.5-50\%), $100 \mathrm{ng} / \mathrm{ml}$ TRAIL, $5 \mathrm{mM} \mathrm{KCl}, 100 \mu \mathrm{M}$ glibenclamide, $100 \mu \mathrm{M}$ U37883A alone or in combination for $1,3,5$ and $10 \mathrm{~min}$. The cells were then measured for fluorescence using a microplate reader (Fluoroskan Ascent) with excitation and emission at 485 and $538 \mathrm{~nm}$ (for Fluo 4-AM) and 542 and $592 \mathrm{~nm}$ (for rhod 2-AM), respectively. For the analyses of $\mathrm{Ca}^{2+}$ release and store-operated $\mathrm{Ca}^{2+}$ entry (SOCE), Fluo4-AM-loaded cells were suspended in a $\mathrm{Ca}^{2+}$-free medium (HBSS supplemented with $1 \mathrm{mM} \mathrm{CaCl}_{2}$ ) and treated with $1 \mu \mathrm{M}$ thapsigargin (Tg) for $10 \mathrm{~min}$ and then added with $2 \mathrm{mM} \mathrm{CaCl}{ }_{2}$. The fluorescence was measured as described above with excitation and emission at 485 and $538 \mathrm{~nm}$. 

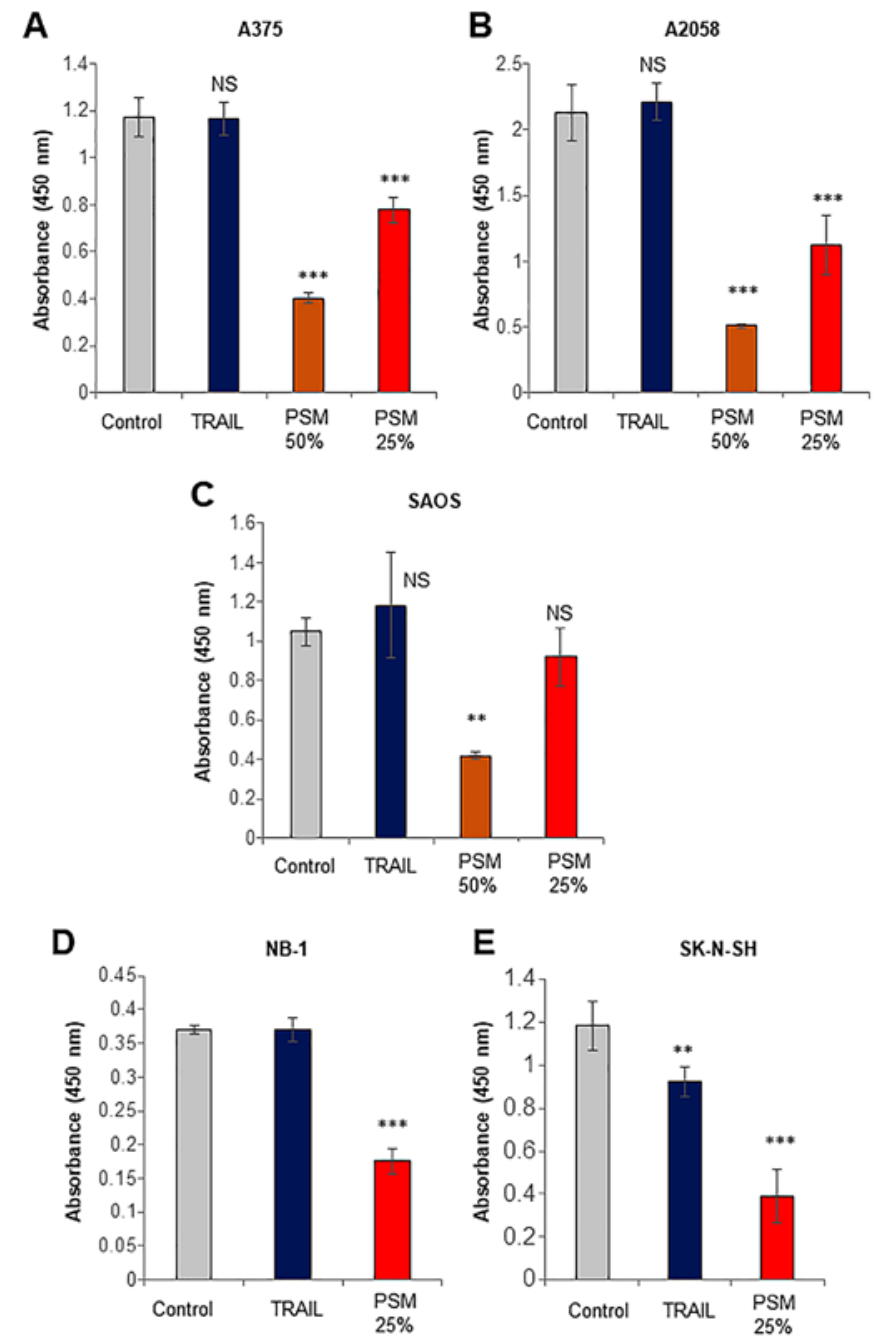

Figure 1. Plasma-stimulated medium (PSM) kills TRAIL-resistant cancer cells from different origins. (A) A375, (B) A2058, (C) SAOS-2, (D) NB-1 and (E) SK-N-SH cells were treated with $100 \mathrm{ng} / \mathrm{ml}$ TRAIL or 25 and $50 \%$ PSM for $72 \mathrm{~h}$ and cell viability was examined by WST- 8 assay in triplicate. The data are the means \pm SD from a representative experiment $(n=3)$. Data were analyzed by ANOVA followed by Tukey's post hoc test. ${ }^{* *} \mathrm{P}<0.01 ;{ }^{* * *} \mathrm{P}<0.001$; and NS, not significant vs. control.

Statistical analysis. Data were analyzed by one-way analysis of variance followed by Tukey's post hoc test using an add-in software for Excel 2016 for Windows (SSRI, Tokyo, Japan). All values are expressed as the means \pm SD and a value of $\mathrm{P}<0.05$ was considered to indicate a statistically significant difference.

\section{Results}

The PSM kills TRAIL-resistant human malignant cells with different origins. First, we systematically compared the capacity of the PSM to kill cancerous cells with that of TRAIL. TRAIL primarily causes cell death by apoptosis in various tumor cell types, including malignant melanoma and osteosarcoma cells (9-15). Treatment with TRAIL at $\leq 100 \mathrm{ng} / \mathrm{ml}$ for $72 \mathrm{~h}$ resulted in a minimal decrease in the viability of A375, A2058, SAOS-2, NB-1 and SK-N-SH cells (Fig. 1), whereas, PSM ( $\geq 25 \%$ ) decreased the viability of the cells. The effect of the PSM was observed as early as $24 \mathrm{~h}$ (data not shown). These
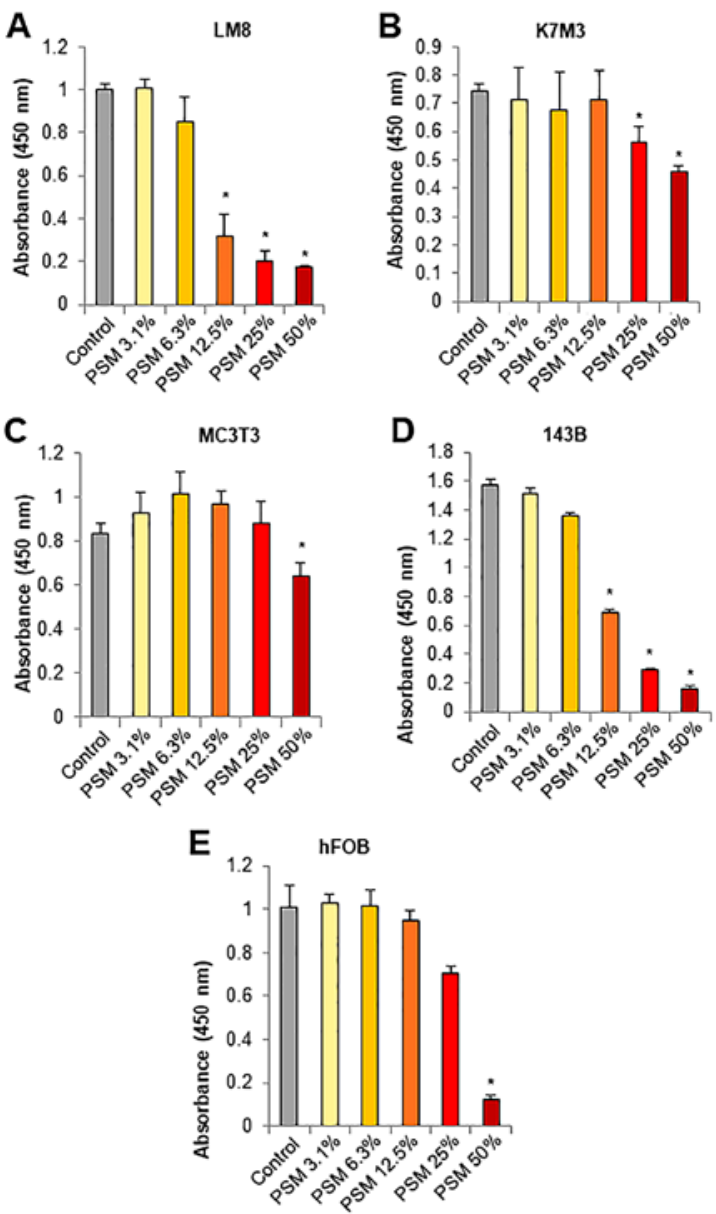

Figure 2. Plasma-stimulated medium (PSM) preferentially causes injuries to transformed cells. (A) LM8, (B) K7M3, (C) MC3T3, (D) 143B and (E) hFOB cells were treated with $3.1-50 \%$ PSM for $72 \mathrm{~h}$, and cell viability was examined by WST- 8 assay in triplicate. The data are the means \pm SD from a representative experiment $(n=3)$; Data were analyzed by ANOVA followed by Tukey's post hoc test. ${ }^{*} \mathrm{P}<0.05$ vs. control.

results indicate that PSM can kill TRAIL-resistant human malignant cells with different origins.

PSM preferentially causes injuries in transformed cells. The most attractive properties of PSM is its high tumor-selective activity. To confirm the properties of PSM, we compared its effect on cell viability between osteosarcoma cells and their normal counterparts, osteoblasts. PSM at concentrations of $\geq 12.5 \%$ decreased the viability of mouse LM8 osteosarcoma cells in a dose-dependent manner ( $\geq 70 \%$ reduction) (Fig. $2 \mathrm{~A}$ ). Moreover, PSM at concentrations ranging from $12.5-50 \%$ had no or smaller effects on the viability of mouse K7M3 and MC3T3 osteoblasts, although the former was more sensitive than the latter (Fig. 2B and C). Similarly, PSM at concentrations of $\geq 12.5 \%$ decreased the viability of human $143 \mathrm{~B}$ osteosarcoma cells in a dose-dependent manner, while it had less potent effects on the viability of human hFOB osteoblasts (Fig. 2D and E). These results expand our previous findings on melanocytes and fibroblasts (45) and indicate that PSM preferentially causes injuries in transformed cells.

PSM cytotoxicity is caspase-independent and superoxidedependent, depending on the cell type. Previous studies 


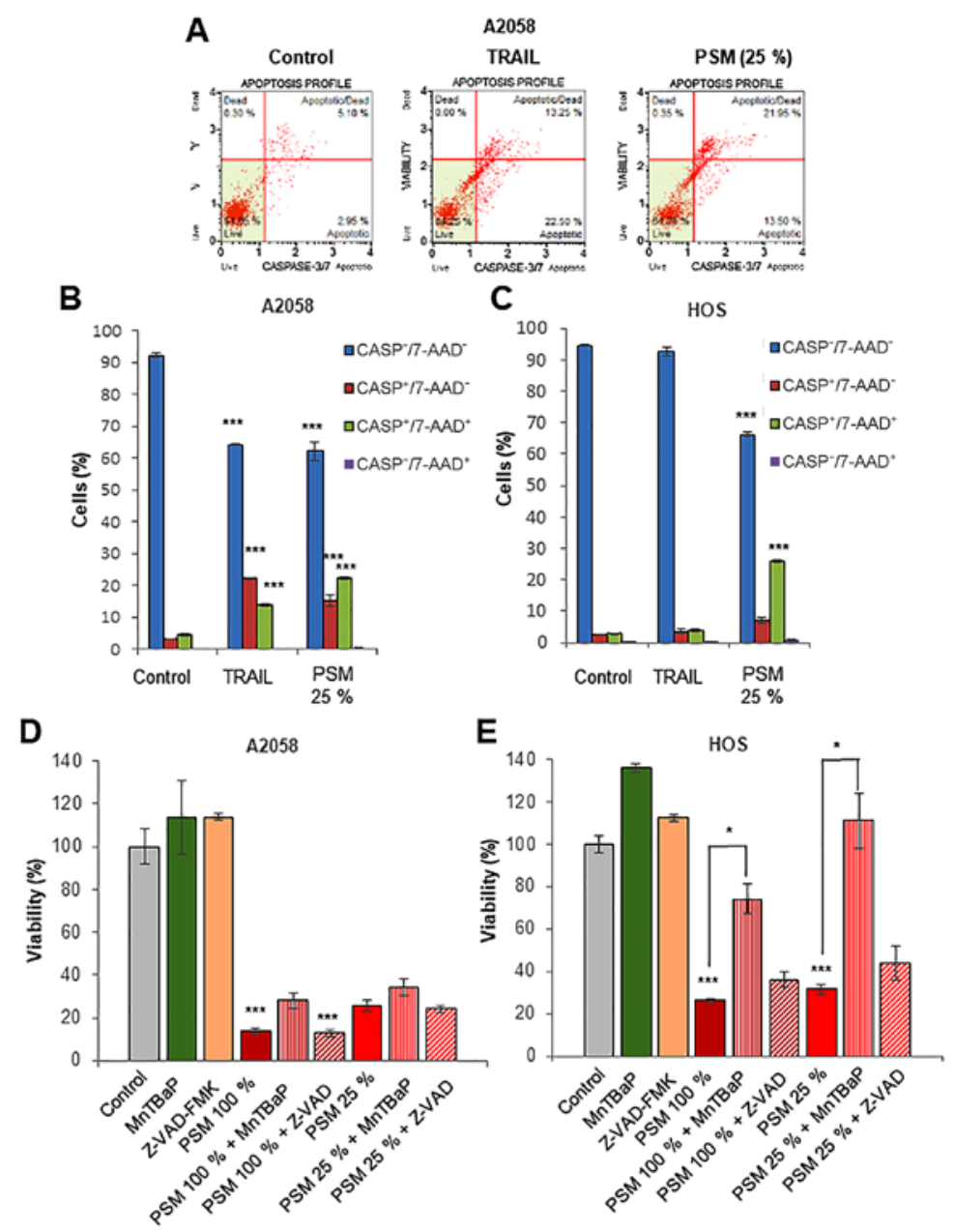

Figure 3. Plasma-stimulated medium (PSM) cytotoxicity is caspase-independent. (A) Representative histogram of A2058 cells. Upper left quadrant, necrotic cells (caspase-/7-AAD $)$; bottom left quadrant, live cells (caspase-/7-AAD); upper right quadrant, late apoptotic cells (caspase ${ }^{+} / 7-\mathrm{AAD}^{+}$); bottom right quadrant, early apoptotic cells (caspase+/7-AAD). (A-D) A2058 cells and (C and E) HOS cells were treated with $100 \mathrm{ng} / \mathrm{ml}$ TRAIL or PSM (25, 100\%) for $72 \mathrm{~h}$ in the (A-C) absence or (D and E) presence of $10 \mu \mathrm{M}$ z-VAD-FMK (Z-VAD) or $30 \mu \mathrm{M} \mathrm{MnTBaP}$. The cells were then examined for caspase-3/7 activation and membrane integrity using NucView ${ }^{\mathrm{TM}}$ and 7-amino-actinomycin D (7-AAD) in a Muse ${ }^{\mathrm{TM}}$ Cell Analyzer in triplicate. The data are the means $\pm \mathrm{SD}$ from a representative experiment $(\mathrm{n}=3)$. Data were analyzed by ANOVA followed by Tukey's post hoc test. ${ }^{*} \mathrm{P}<0.05 ;{ }^{* * * *} \mathrm{P}<0.001$.

have demonstrated that apoptosis is the primary mechanism of PSM-induced in vitro killing of different types of tumors, including colon ovarian, lung, cancer and glioblastoma (48-51). On the other hand, we previously demonstrated that PSM cytotoxicity toward melanoma cells was not inhibited by the caspase-3/7-specific inhibitor, z-DEVD-FMK, while PSM increased the number of caspase-3/7-activated cells. Moreover, PSM caused the minimal cleavage of caspase-3/7 and poly ADP-ribose polymerase, a substrate of caspase-3/7 (45). These findings suggest that the cell death caused by PSM differs from canonical apoptosis. To test this view, in this study, we monitored caspase-3/7 activation and cell death concomitantly using $\mathrm{NucView}^{\mathrm{TM}}$ and 7-AAD staining. NucView ${ }^{\mathrm{TM}}$ is a novel caspase-3/7 substrate and 7-AAD is a dead cell marker, which is excluded from healthy and early apoptotic cells, while permeates late apoptotic and dead cells. Accordingly, we could distinguish 4 cell populations by this method: Live cells, caspase3/7-inactivated, 7-AAD-negative (caspase-/7-AAD); early apoptotic cells, caspase-3/7-activated, 7-AAD-negative (caspase +7 -AAD); late apoptotic/dead cells, caspase-3/7-activated, 7-AAD-positive (caspase ${ }^{+} / 7-\mathrm{AAD}^{+}$); and necrotic cells, caspase-3/7-inactivated, 7-AAD-positive (caspase/7-AAD ${ }^{+}$. Treatment of the A2058 cells with TRAIL or PSM $(25 \%)$ for $24 \mathrm{~h}$ resulted in a comparable decrease in the number of live cells ( $35 \%$ reduction). However, TRAIL preferentially increased the number of caspase ${ }^{+} / 7-\mathrm{AAD}^{-}$cells than that of caspase ${ }^{+} / 7-\mathrm{AAD}^{+}$cells, while PSM preferentially increased the number of caspase ${ }^{+} / 7-\mathrm{AAD}^{+}$cells than that of caspase $^{+} / 7-\mathrm{AAD}^{-}$cells (Fig. 3A and B). Moreover, PSM, but not TRAIL, caused a robust decrease in the number of live HOS cells (30\%), in association with an increased number of caspase $^{+} / 7-\mathrm{AAD}^{+}$cells (Fig. 3C). When applied for $72 \mathrm{~h}$, the cytotoxicity of PSM (25 and 100\%) toward the HOS, but not the A2058 cells, was significantly inhibited by the treatment with superoxide mimetic, MnTBaP $(30 \mu \mathrm{M})$ for $72 \mathrm{~h}$, and these effects were more pronounced for the low concentration of PSM (Fig. 3D and E). By contrast, treatment with the pan-caspase-inhibitor, z-VAD-FMK $(10 \mu \mathrm{M})$ for $72 \mathrm{~h}$, had no inhibitory effect regardless of the cell type, and the concentration of PSM employed. These results indicate that despite its ability to evoke caspase-3/7 activation, PSM cytotoxicity is primarily caspase-independent and is superoxide-dependent, depending on the cell type. 
A $\mathbf{A 2 0 5 8}$
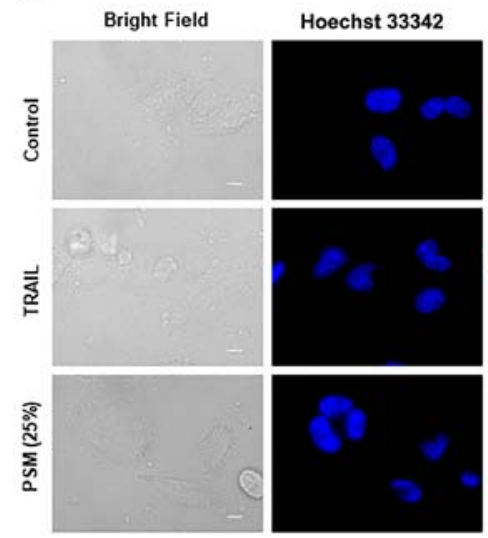

B

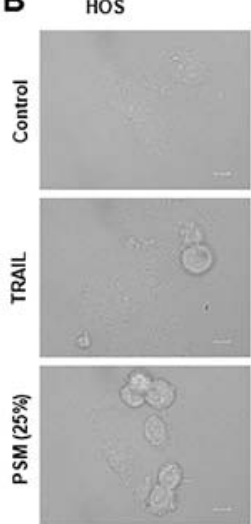

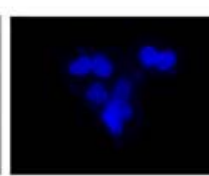
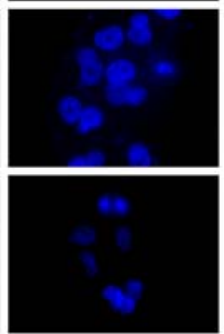

MitoTracker
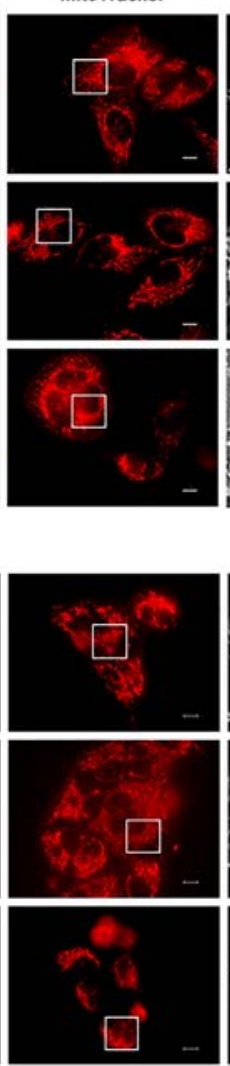

Zoom
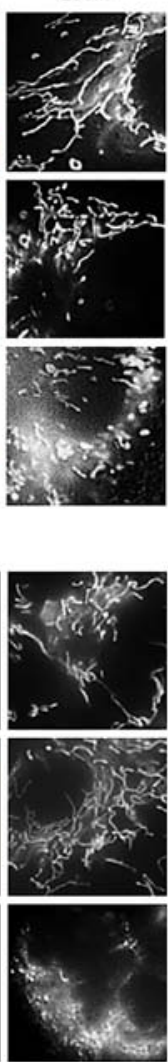

C
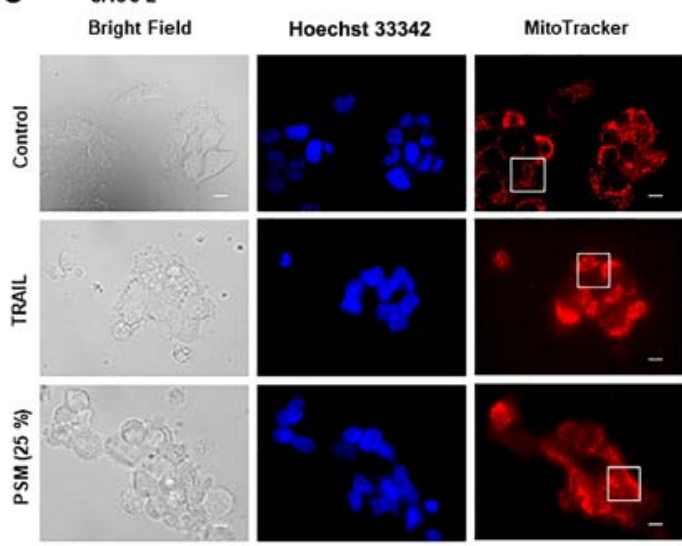

D SK-N-SH
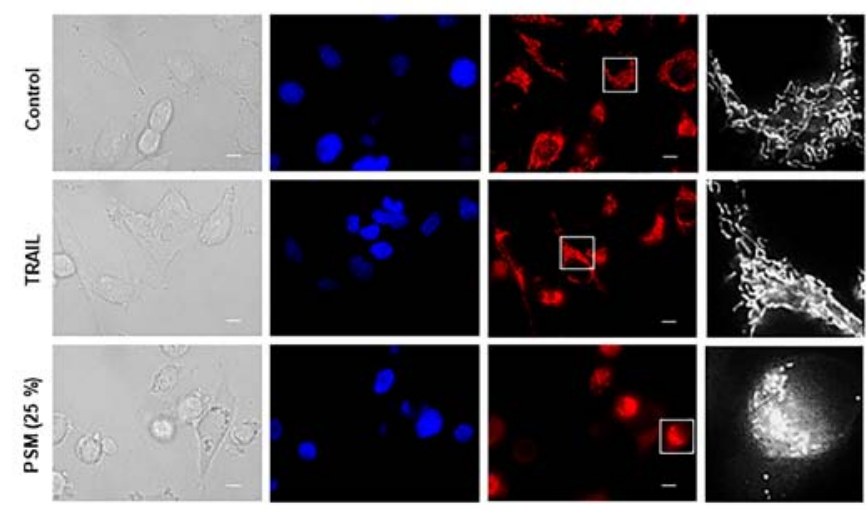

Figure 4. Plasma-stimulated medium (PSM) is more potent than TRAIL in inducing mitochondrial network aberration. (A) A2058, (B) HOS, (C) SAOS-2, and (D) SK-N-SH cells were treated with $100 \mathrm{ng} / \mathrm{ml}$ TRAIL or the PSM (25\%) for $24 \mathrm{~h}$ at $37^{\circ} \mathrm{C}$. After washing, the cells were stained with Hoechst 33342 and MitoTracker Red CMXRos for $1 \mathrm{~h}$ and washed again. Images were obtained using a BZ X-700 Fluorescence Microscope equipped with a X100, 1.40 n.a. UPlanSApo Super-Apochromat, coverslip-corrected oil objective and analyzed using BZ-H3A application software and free NIH ImageJ software. The panels labeled 'Zoom' represent images of the expansion of the small white boxes within the images in the previous panel on the left. Scale bar, $10 \mu \mathrm{m}$.

PSM is more potent than TRAIL in inducing mitochondrial network aberration. We then directly compared the effects of TRAIL and the PSM on mitochondrial morphology in different tumor cell types. After treating the cells for $24 \mathrm{~h}$, the mitochondria were stained with the mitochondrialtargeting dye, MitoTracker Red CMXRos, and the nuclei were counterstained with Hoechst 33342. The A2058, HOS, SAOS-2, SK-N-SH cells were all highly adherent spindle cells that displayed tubular mitochondrial morphology around healthy nuclei in the absence of an insult (Fig. 4A-D, upper panels). TRAIL treatment resulted in minimal cellular and nuclear morphological changes, and a modest mitochondrial fragmentation in all cell types apart from the SAOS-2 cells (Fig. 4A-D, middle panels). We found that this cell type was frequently considerably damaged by TRAIL treatment. In this case, a substantial amount of cells became round in shape and eventually became detached from the coverslips (Fig. 4C). In these cells, the mitochondria became heavily fragmented and clustered. In all cell types tested, PSM (25\%) caused a more profound impact than TRAIL $(\leq 100 \mathrm{ng} / \mathrm{ml})$ on cellular and mitochondrial morphology. PSM treatment led to a considerable increase in the amount of round, damaged cells that possessed punctate and clustered mitochondria, as well as broken nuclei (Fig. 4A-D, lower panels). These results indicate that PSM is more potent than TRAIL in inducing mitochondrial network aberration.
PSM, but not TRAIL, evokes rapid and persistent PMD. Previously, we demonstrated that PMD is a critical cellular event in TRAIL-induced apoptosis and is essential for the mitochondrial network aberration in different malignant cell types $(52,53)$. This finding led us to compare the ability evoked PMD between PSM and TRAIL. In this study, analysis using the voltage-sensitive fluorescence probe $\operatorname{DiBAC}_{4}(3)$ revealed that in all cell lines tested (A2058, HOS, SAOS-2 and NB-1), PSM treatment resulted in robust PMD within $1 \mathrm{~min}$, which lasted at least for $10 \mathrm{~min}$ (Fig. 5A-D). PSM ( $\geq 25 \%$ ) exerted its effect in a dose-dependent manner (data not shown). By contrast, TRAIL $(\leq 100 \mathrm{ng} / \mathrm{ml})$ caused minimal PMD until the 10-min time point, regardless of the cell types tested. We noted that in parallel with the cellular sensitivity to PSM, the degree of PMD varied considerably in different experiments. Accordingly, in some cases, PSM $(\leq 50 \%)$ induced minimal PMD or membrane hyperpolarization instead (Fig. 5E and F). The ATP-sensitive potassium channel $\left(\mathrm{K}_{\mathrm{ATP}}\right)$ antagonist, glibenclamide, constantly evoked persistent PMD. These results indicate that PSM, but not TRAIL, elicits rapid, persistent PMD in malignant cells with different origins.

Enforced PMD promotes TRAIL-induced caspase-independent cell killing and mitochondrial network aberration. To explore the link between PMD and cell killing, we examined whether enforced PMD enhances caspase-independent cell 
A
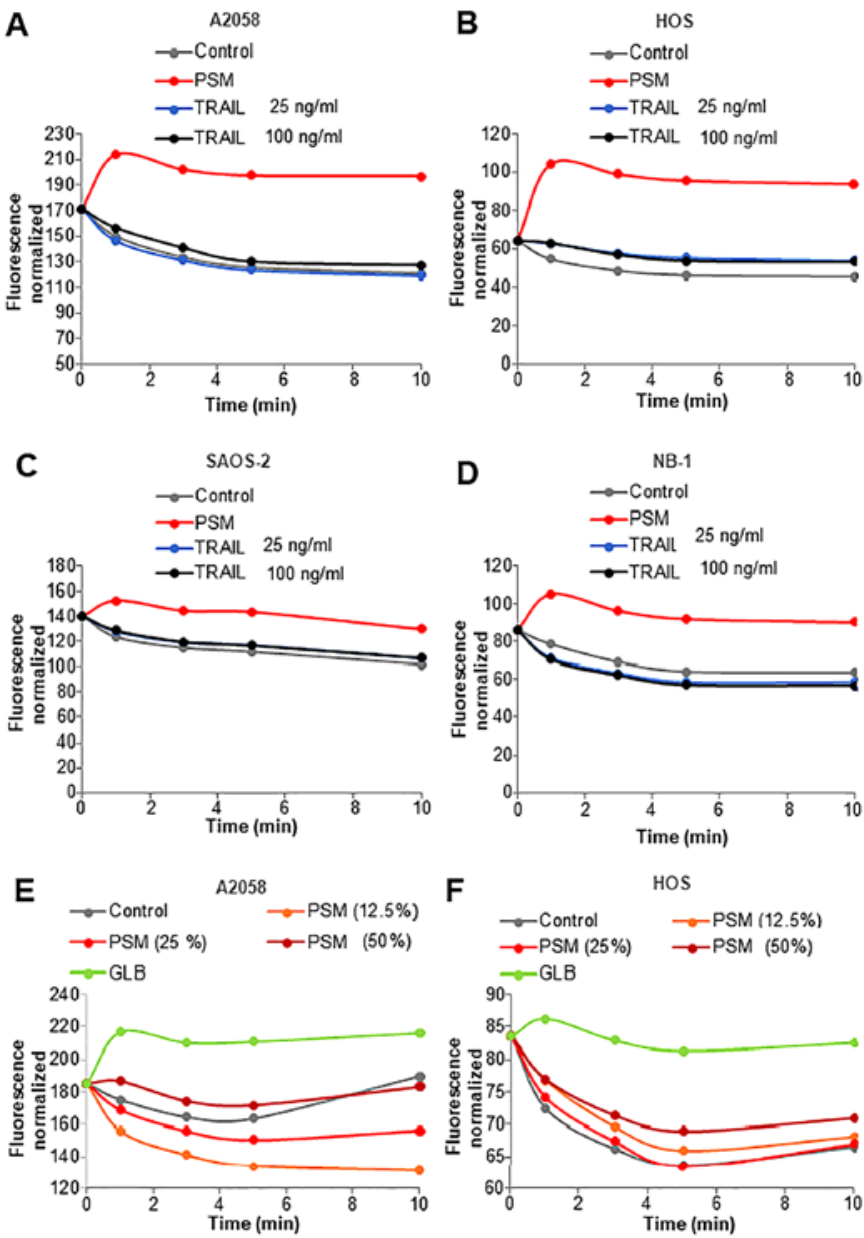

Figure 5. Plasma-stimulated medium (PSM) evokes rapid and persistent plasma membrane depolarization (PMD). (A) A2058 and (B) HOS (C) SAOS-2, and (D) NB-1 cells, were loaded with $5 \mathrm{M} 5 \mu \mathrm{M} \mathrm{DiBAC}{ }_{4}(3)$ for $40 \mathrm{~min}$ at $37^{\circ} \mathrm{C}$. The probe-loaded cells were washed, resuspended in HBSS, treated with PSM $(25 \%)$ or $25,100 \mathrm{ng} / \mathrm{ml}$ TRAIL, and measured for their fluorescence for $1,3,5$ and $10 \mathrm{~min}$ in a microplate fluorescence reader with excitation and emission at 485 and $538 \mathrm{~nm}$. (E) A2058 and (F) HOS cells were loaded with $\operatorname{DiBAC}_{4}(3)$ as shown above and treated with PSM (12.5-50\%) or $100 \mathrm{M}$ glibenclamide (GLB), and measured for their fluorescence for 1, 3, 5 and $10 \mathrm{~min}$ in a microplate fluorescence reader with excitation and emission at 485 and $538 \mathrm{~nm}$. The data are expressed as the fluorescence intensity normalized (per $1 \times 10^{6}$ cells)

killing by TRAIL. While TRAIL $(100 \mathrm{ng} / \mathrm{ml})$ and glibenclamide $(100 \mu \mathrm{M})$ alone had only a modest effect on cell viability ( $\leq 20 \%$ decrease), their combined use profoundly decreased the viability of the A2058, SAOS-2 and SK-N-SH cells ( $\geq 70 \%$ reduction) (Fig. $6 \mathrm{~A}$ ). The other membrane-depolarizing agents, such as potassium chloride $(\mathrm{KCl})(50 \mathrm{mM})$ and another type of $\mathrm{K}_{\mathrm{ATP}}$ inhibitor, U37883A, also caused a synergistic cytotoxic effect with TRAIL. By contrast, the oxidative phosphorylation (OXOPHOS) inhibitor, FCCP (5 $\mu \mathrm{M})$, which sensitizes melanoma and osteosarcoma cells to TRAIL-induced apoptosis $(47,53)$ was generally ineffective in the cells tested, aparat from the SK-N-SH cells. In the A2058 and SAOS-2 cells, the cell death caused by TRAIL and either membrane-depolarizing agents was not inhibited by $\mathrm{z}$-VAD-FMK, indicating that it is caspase-independent, as that produced by PSM. Moreover, in the SK-N-SH cells, the cell death induced by TRAIL and glibenclamide or FCCP
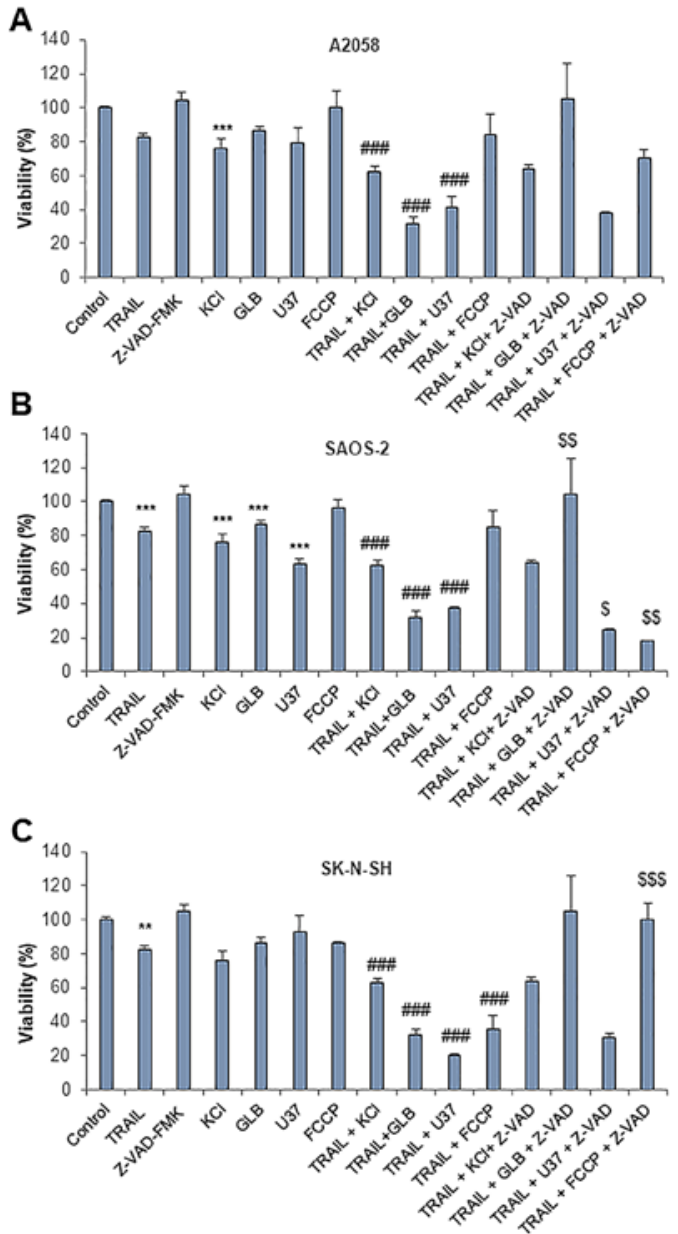

Figure 6. Enforced plasma membrane depolarization (PMD) promotes TRAIL-induced caspase-independent cell killing. (A) A2058, (B) SAOS-2, and (C) SK-N-SH cells were treated with $100 \mathrm{ng} / \mathrm{ml}$ TRAIL, $50 \mathrm{mM} \mathrm{KCl}$, $100 \mu \mathrm{M}$ glibenclamide (GLB), $100 \mu \mathrm{M} \mathrm{U37883A}$ (U37), and $5 \mu \mathrm{M}$ FCCP alone or in combination in the absence or presence of $10 \mu \mathrm{M} \mathrm{z}$-VAD-FMK (Z-VAD) for $72 \mathrm{~h}$ at $37^{\circ} \mathrm{C}$. Cell viability was then examined by WST- 8 assay in triplicate. The data are the means \pm SD from a representative experiment $(n=3)$. Data were analyzed by ANOVA followed by Tukey's post hoc test. ${ }^{* *} \mathrm{P}<0.01 ;{ }^{* * *} \mathrm{P}<0.001$ vs. control. ${ }^{\# \# \#} \mathrm{P}<0.001$ vs. TRAIL alone; ${ }^{\$} \mathrm{P}<0.05$; ${ }^{\$ \$} \mathrm{P}<0.01 ;{ }^{\$ \$} \mathrm{P}<0.001$ vs. TRAIL + agent in the absence of Z-VAD.

was entirely blocked by z-VAD-FMK (Fig. 6C), indicating that it is caspase-dependent. We then examined the effects on mitochondrial morphology. Glibenclamide alone caused substantial mitochondrial fragmentation (Fig. 7A and B, third panels), and when applied in conjunction with TRAIL, led to the clustering of punctate, swollen mitochondria in A2058 and SAOS-2 cells (Fig. 7A and B, fifth panels). The combined use of TRAIL and GLB also resulted in cell damage and nuclear fragmentation. U37883A exerted essentially similar effects (Fig. 7B, fourth and bottom panels).

PSM is more potent than TRAIL in disrupting $\mathrm{Ca}^{2+}$ homeostasis. Recently, we demonstrated that $\mathrm{Ca}^{2+}$ dynamics, particularly those in the mitochondrial matrix, are a critical regulator of mitochondrial morphology and death in melanoma and osteosarcoma cells. Specifically, increasing $\left[\mathrm{Ca}^{2+}\right]_{\text {mit }}$ resulted in mitochondrial fragmentation, while decreasing $\left[\mathrm{Ca}^{2+}\right]_{\text {mit }}$ led to mitochondrial hyperfusion $(46,47)$. These observations led us to compare their ability to modulate $\mathrm{Ca}^{2+}$ dynamics between 


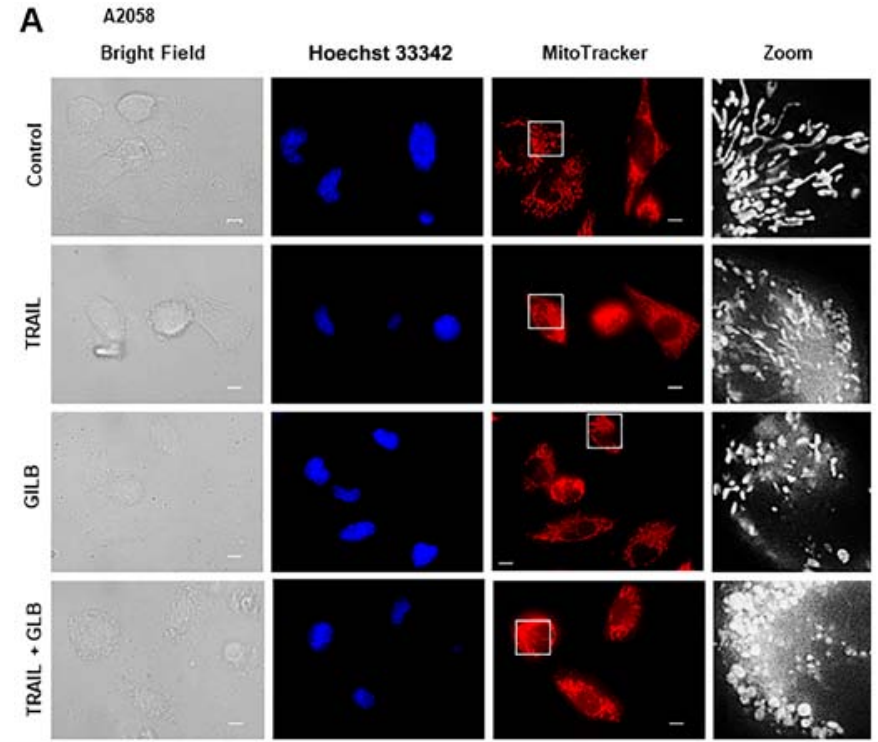

B SAOS.2

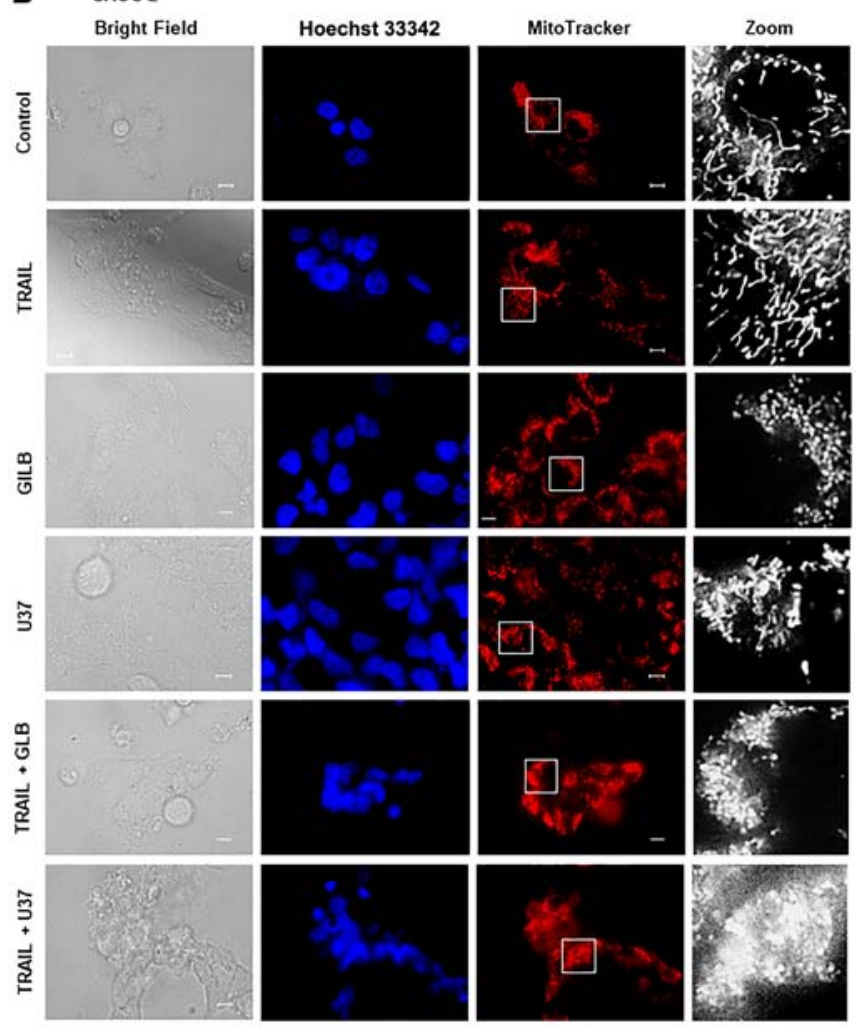

Figure 7. Enforced plasma membrane depolarization (PMD) promotes TRAIL-induced mitochondrial network aberration. (A) A2058 and (B) SAOS-2 cells were treated with $100 \mathrm{ng} / \mathrm{ml} \mathrm{TRAIL}, 100 \mu \mathrm{M}$ glibenclamide (GLB) and $100 \mu \mathrm{M} \mathrm{U} 37883 \mathrm{~A}$ (U37) alone or in combination for $24 \mathrm{~h}$ at $37^{\circ} \mathrm{C}$. The cells were then examined for cellular, mitochondrial, and nuclear morphological changes as described in the legend of Fig. 4. The panels labeled 'Zoom' represent images of the expansion of the small white boxes within the images in the previous panel on the left. Scale bar, $10 \mu \mathrm{m}$.

TRAIL and PSM. In this study, we first examined whether these two insults have any affect on intracellular $\mathrm{Ca}^{2+}$ stores and extracellular $\mathrm{Ca}^{2+}$ influx. Treatment with the $\mathrm{Ca}^{2+}$-ATPase inhibitor, thapsigargin ( $\mathrm{Tg}$ ), in a $\mathrm{Ca}^{2+}$-free medium followed by the addition of $\mathrm{Ca}^{2+}$ resulted in a rapid small rise and a higher degree of elevation in $\left[\mathrm{Ca}^{2+}\right]_{\mathrm{cyt}}$ (Fig. 8A). It is established that the former represents $\mathrm{Ca}^{2+}$ release from the intracellular stores mainly the endoplasmic reticulum (ER), while the latter depicts the SOCE. Treatment with PSM $(\geq 25 \%)$ led to a marked increase in $\mathrm{Ca}^{2+}$ release in a dose-dependent manner (Fig. 8B). By contrast, treatment with TRAIL at up to $100 \mathrm{ng} / \mathrm{ml}$ had no significant effect on $\mathrm{Ca}^{2+}$ release (Fig. 8C). Morever, treatment with PSM $(\geq 25 \%)$, but not TRAIL, decreased SOCE (Fig. 8D and E). The combined use of TRAIL and $100 \mu \mathrm{M}$ each of glibenclamide or U37883A led to reduced SOCE, as did the combined application of TRAIL and the OXOPHOS inhibitors, FCCP $(5 \mu \mathrm{M})$ and antimycin A $(5 \mu \mathrm{g} / \mathrm{ml})$ for $10 \mathrm{~min}$. However, none of these agents resulted in an increased $\mathrm{Ca}^{2+}$ release from the intracellular stores (Fig. 8F).

Enforced PMD enables TRAIL to mimic the effects of PSM on $\left[\mathrm{Ca}^{2+}\right]_{m i t}$. An excess, persistent elevation in $\left[\mathrm{Ca}^{2+}\right]_{c y t}$ is the primary cause of cell death. Specifically, mitochondrial $\mathrm{Ca}^{2+}$ overload triggers necrosis and apoptosis (31-34). Thus, to further explore the link between $\mathrm{Ca}^{2+}$ dyshomeostasis and tumor cell death, we examined the effect of the insults on $\left[\mathrm{Ca}^{2+}\right]_{\text {cyt }}$ and $\left[\mathrm{Ca}^{2+}\right]_{\text {mit }}$. For this purpose, we concomitantly measured $\mathrm{Ca}^{2+}$ concentrations in the two different intracellular sites using the site-specific $\mathrm{Ca}^{2+}$ probes, Fluo4-AM and rhod-2-AM. PSM led to a rapid increase in $\left[\mathrm{Ca}^{2+}\right]_{\mathrm{cyt}}$ in the HOS cells. The effect was observed within $1 \mathrm{~min}$ and lasted at least 10 min. PSM exerted its effect in a dose-dependent manner with the minimal effective concentration of $12.5 \%$ (Fig. 9A and E). Concomitantly, the levels of $\left[\mathrm{Ca}^{2+}\right]_{\text {mit }}$ also increased with similar kinetics, although the effects of PSM at concentrations of 12.5 to $50 \%$ were comparable (Fig. 9B and F). TRAIL resulted in a much smaller increase in the levels of $\left[\mathrm{Ca}^{2+}\right]_{\text {cyt }}$ while glibenclamide, U37883A and $\mathrm{KCl}$ alone led to a decrease in the levels of $\left[\mathrm{Ca}^{2+}\right]_{\text {cyt }}$ (Fig. 9C). Even when used together, no significant increase in $\left[\mathrm{Ca}^{2+}\right]_{\text {cyt }}$ levels was observed (Fig. 9C and E). Moreover, either membrane-depolarizing agent alone promptly resulted in a small, but persistent increase in $\left[\mathrm{Ca}^{2+}\right]_{\text {mit }}$ (Fig. 9D and F). The combined use of TRAIL and the membrane-depolarizing agent led to a greater extent of $\left[\mathrm{Ca}^{2+}\right]_{\text {mit }}$ rise comparable to that induced by PSM at concentrations of 12.5 to $50 \%$ (Fig. 9F). We obtained substantially the same results for SAOS-2 cells (data not shown). These results indicate that the PSM is a potent inducer of the increase in $\left[\mathrm{Ca}^{2+}\right]_{\text {cyt }}$ and $\left[\mathrm{Ca}^{2+}\right]_{\text {mit }}$, and the combined use of TRAIL and the membrane-depolarizing agent can mimic the effect of PSM on $\left[\mathrm{Ca}^{2+}\right]_{\text {mit }}$, but not $\left[\mathrm{Ca}^{2+}\right]_{\text {cyt }}$ levels.

\section{Discussion}

CAP/PSM has emerged as a promising tool for the treatment of aggressive tumors. In the present study, we systematically compared the antitumor activity of PSM with that of TRAIL. PSM prepared by irradiating cold plasma to DMEM killed different malignant cell types (malignant melanoma, osteosarcoma, and neuroblastoma) that were highly resistant to TRAIL (Fig. 1), whereas, PSM had little cytotoxic effects on murine and human osteoblasts (Fig. 2). The findings expand our previous observations on melanocytes and fibroblasts (28), and indicate that PSM preferentially causes injuries to malignant cells. PSM prepared from different types of gases and media has been shown to kill an array of malignant cells, including 

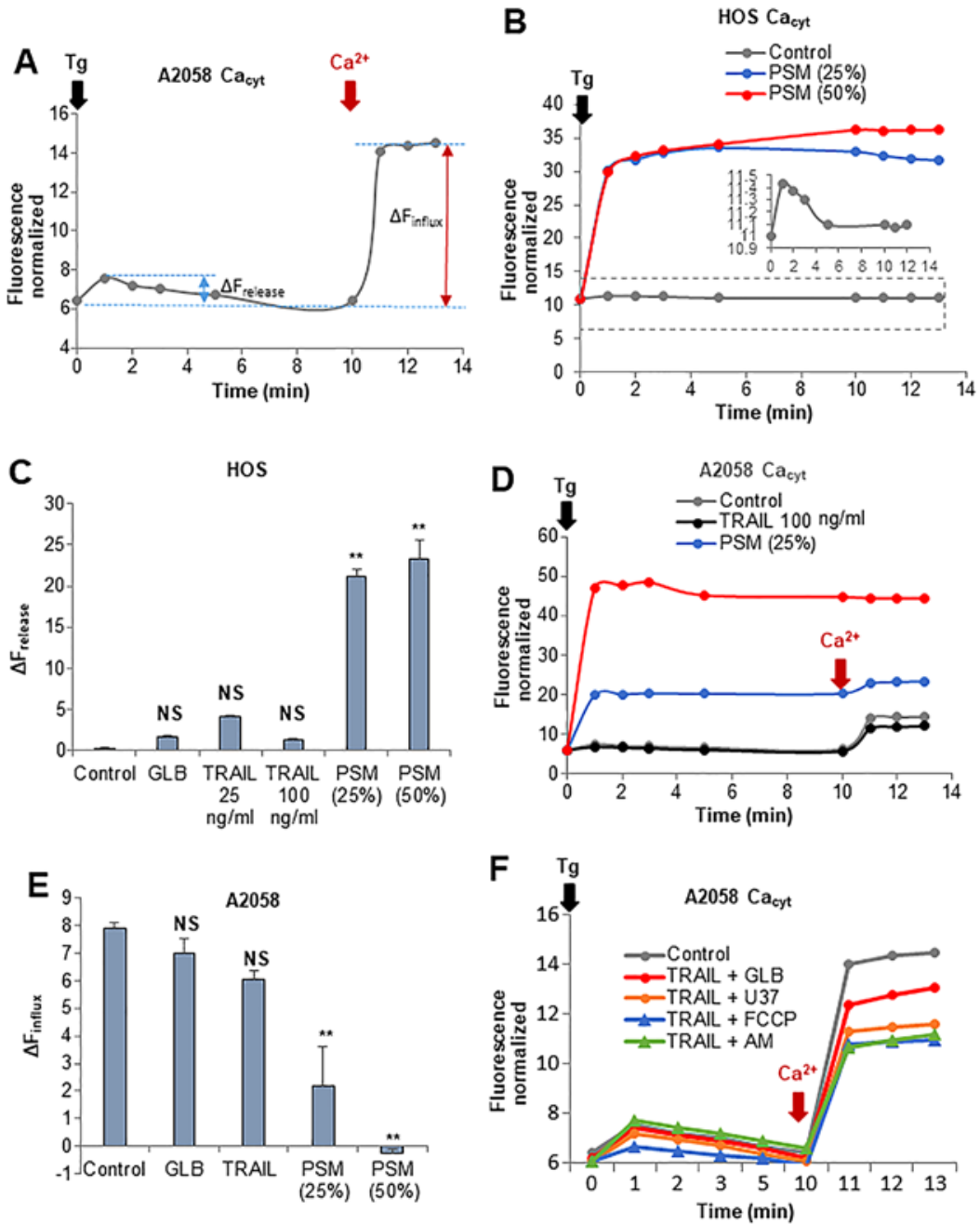

Figure 8. Plasma-stimulated medium (PSM) is more potent than TRAIL in disrupting $\mathrm{Ca}^{2+}$ homeostasis. (A, D, E and F) A2058 and (B and C) HOS cells were suspended in a $\mathrm{Ca}^{2+}$-free buffer (HBSS supplemented with $1 \mathrm{mM} \mathrm{EGTA}$ ) and were loaded with Fluo4-AM. The probe-loaded cells were treated with $100 \mathrm{ng} / \mathrm{ml}$ TRAIL, the PSM (25,50\%), $100 \mu \mathrm{M}$ glibenclamide (GLB), $100 \mu \mathrm{M}$ U37883A (U37), and $5 \mu \mathrm{M}$ FCCP alone or in combination. The cells were immediately supplemented with $2 \mu \mathrm{M}$ thapsigargin ( $\mathrm{Tg}$, black arrow) and incubated for $10 \mathrm{~min}$ to deplete the intracellular $\mathrm{Ca}^{2+}$ stores. Subsequently, $2 \mathrm{mM} \mathrm{Ca}{ }^{2+}$ was added to the cells (dark red arrow). Following the addition of Tg, fluorescence was monitored at 1,2,3,5,10,11, 12 and 13 min with excitation and emission at 485 and $538 \mathrm{~nm}$. (A) Representative $\left[\mathrm{Ca}^{2+}\right]_{\text {cyt }}$ changes in the $\mathrm{Ca}^{2+}$ readdition experiments. The data in $(\mathrm{C}$ and $\mathrm{E})$ represent the means $\pm \mathrm{SD}(\mathrm{n}=3)$ of $\Delta \mathrm{F}_{\text {release }}$ and $\Delta \mathrm{F}_{\text {influx }}$, respectively. Data were analyzed by ANOVA followed by Tukey's post hoc test; ${ }^{* *} \mathrm{P}<0.01 ; \mathrm{NS}$, not significant vs. control. $\Delta \mathrm{F}_{\text {release }}$, fluorecence intensity changes in $\mathrm{Ca}^{2+}$ release; $\Delta \mathrm{F}_{\text {influx }}$, fluorecence intensity changes in $\mathrm{Ca}^{2+}$ influx.

colon cancer ovarian cancer, lung cancer and glioblastoma (48-51). Most of these types of PSM elicit their antitumor activity by primarily stimulating apoptosis. The PSM in our study induced a robust caspase-3/7 activation in A2058 and HOS cells prior to cell death (Fig. 3), indicating that apoptosis occurs in our cell system. Nevertheless, cell death was minimally affected by z-VAD-FMK (Fig. 3). The results expand our previous observations (45) on melanoma cells in that the caspase-3/7-specific inhibitor, z-DEVD-FMK, did not block the cell death induced by PSM. Collectively, these findings suggest that PSM primarily leads to caspase-independent cell death in melanoma and osteosarcoma cells, while apoptosis plays a minor role.

It is widely accepted that RONS play a pivotal role in mediating the antitumor activity of CAP and PSM $(19,21,45)$. In agreement with this view, $N$-acetylcysteine (NAC), a broadspectrum antioxidant has been shown to markedly inhibited cell death caused by PSM in melanoma, osteosarcoma and lung cancer cells (45). Moreover, in that study, PSM led to a rapid mitochondrial superoxide generation in all cell types tested, as detected by the mitochondrial-targeting superoxide probe, MitoSOX. These observations suggest that RONS originated from superoxide are critical mediators of antitumor activity. Nevertheless, we noted that MnTBaP, a superoxide-mimetic failed to block the antitumor activity against melanoma cells such as A375 and A2058 (45). Consistent with the findings of our previous study, the present study revealed that MnTBaP actively blocked HOS cell death, while it minimally inhibited A2058 cell death (Fig. 3). Of note, there was a tendency that MnTBaP was effective when the concentration of PSM was low. The findings strongly suggest that the actual RONS that are responsible for the antitumor activity of PSM may be differ depending on the cell type and the concentration of PSM used.

We have previously demonstrated that the mitochondrial network dynamics is another common target for the two insults in damaging cells $(44,45)$. The direct comparison of their effects on the mitochondrial morphology revealed that PSM was more potent than TRAIL in evoking mitochondrial 
A
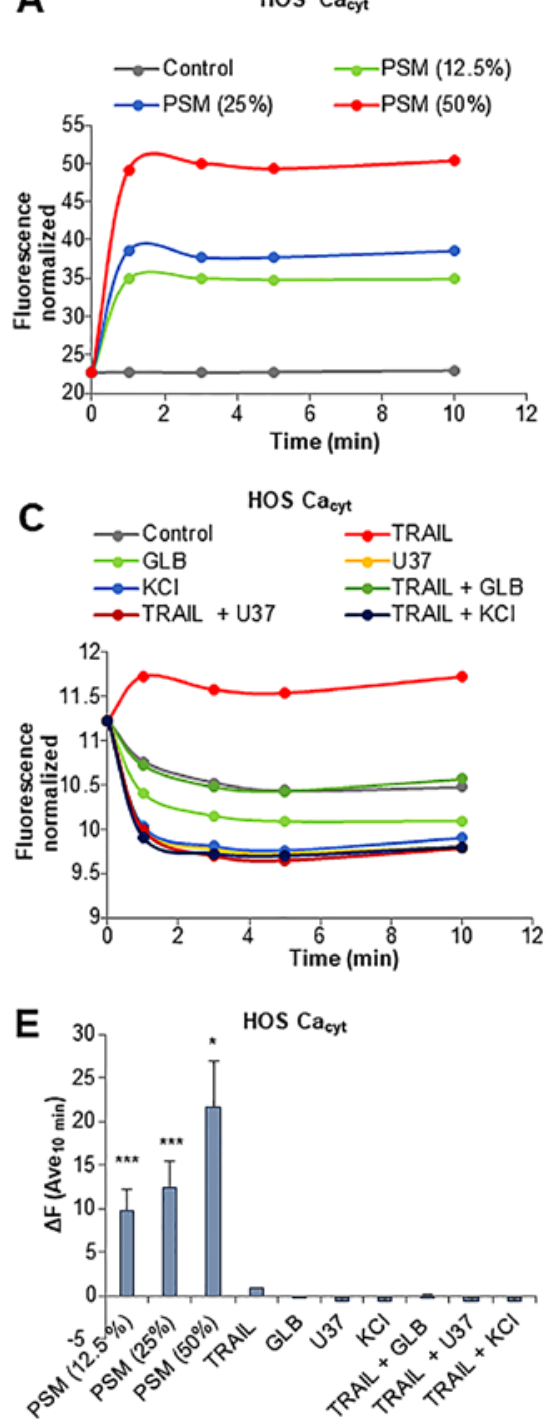

B
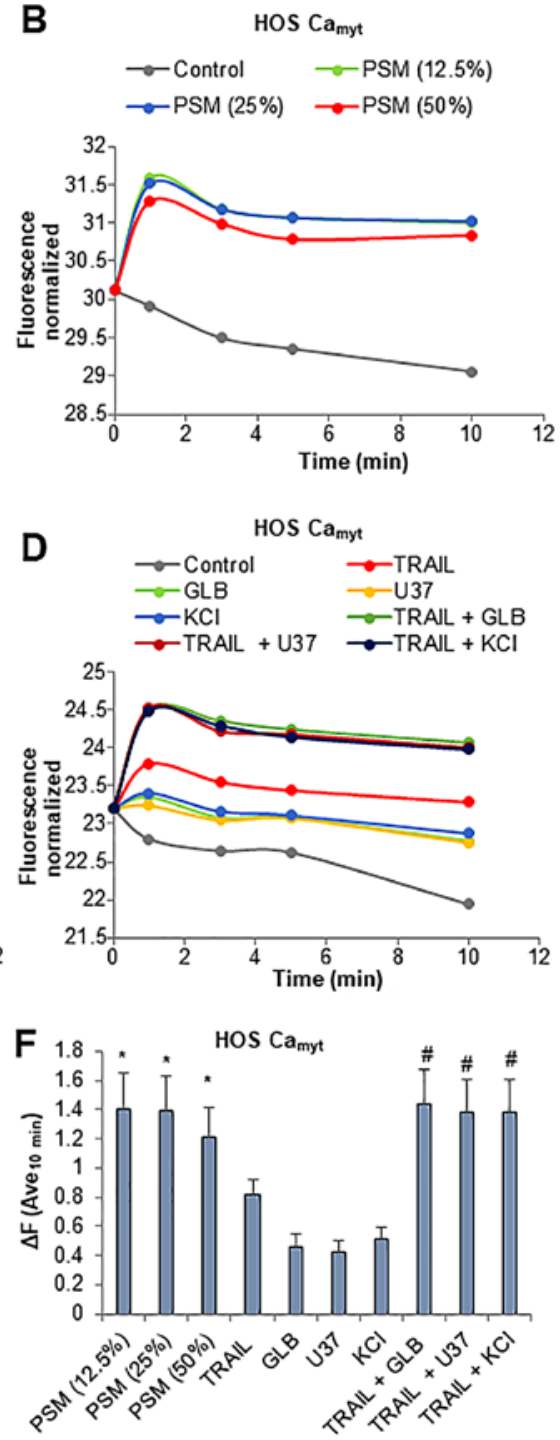

Figure 9. Enforced plasma membrane depolarization (PMD) facilitates TRAIL to mimic the effect of the PSM on $\left[\mathrm{Ca}{ }^{2+}\right]_{\text {mit }} . \mathrm{HOS}$ cells were loaded with $(\mathrm{A}, \mathrm{C}$ and E) Fluo 4-AM or (B, D and F) dihydrorhod 2-AM and resuspended in the $\mathrm{Ca}^{2+}$-containing medium. The probe-loaded cells were treated with (A and B) PSM (12.5-50\%), or (C, D, E and F) $100 \mathrm{ng} / \mathrm{ml}$ TRAIL and $50 \mathrm{mM} \mathrm{KCl,} 100 \mu \mathrm{M}$ glibenclamide (GLB) and 100 $\mu \mathrm{M}$ U37883A (U37) alone or in combination. The cells were then measured for fluorescence in triplicate. The data in (E and F) represent the means \pm SD of the average value of changes in fluorecence intensity $(\Delta \mathrm{F})$ for $10 \mathrm{~min}$ in a representative experiment $(\mathrm{n}=3)$. Data were analyzed by ANOVA followed by Tukey's post hoc test; ${ }^{*} \mathrm{P}<0.05$; ${ }^{* * *} \mathrm{P}<0.001$ vs. control; ${ }^{\#} \mathrm{P}<0.05$ vs. TRAIL alone.

network aberration, regardless of the tumor cell types examined. Even the cellular conditions where TRAIL led to only a modest mitochondrial fragmentation, PSM always led to an excessive mitochondrial fragmentation and the clustering of the fragmented mitochondria (Fig. 4). The intense mitochondrial network aberration well-correlated with cell damage, as indicated by the cellular and nuclear morphological changes. These findings suggest that PSM is advantageous over TRAIL in inducing the pro-death mitochondrial network aberration. Our previous study demonstrated that persistent PMD plays a critical role in the progression from a modest mitochondrial fragmentation to an excessive mitochondrial fragmentation and clustering (44). Strikingly, in the present study, we found that PSM was more potent than TRAIL in inducing PMD (Fig. 5). In agreement with our previous findings (52), TRAIL led to a substantial PMD with a delay of 2-4 h. Moreover, PSM caused robust
PMD very rapidly (within $1 \mathrm{~min}$ ) and persistently (at least for $10 \mathrm{~min}$ ). We also observed significant mitochondrial morphological change at as early as $5 \mathrm{~min}$ after PSM treatment, while it occurred with a delay of 2-4 h following TRAIL treatment (data not shown). These findings are consistent with the view that PMD is a critical promoter of the mitochondrial network aberration. Furthermore, we found that enforced PMD by $\mathrm{KCl}$ and $\mathrm{K}_{\mathrm{ATP}}$ antagonists enhanced the mitochondrial network aberration and cell killing caused by TRAIL (Figs. 6 and 7). PMD has been considered to be linked to apoptosis primarily. Apoptosis is characterized by cell shrinkage, which is caused by the disruption of the maintenance of physiological concentrations of $\mathrm{K}^{+}$and $\mathrm{Na}^{+}$and intracellular ion homeostasis $(55,56)$. The loss of these monovalent ions has been shown to facilitate caspase-3 activation (56). The loss also leads to PMD. Indeed, PMD is an early event in apoptosis induced by 
diverse insults including TRAIL, Fas, arsenic trioxide and rotenone (57-59). Consistent with this view, glibenclamide, which caused persistent PMD, amplified TRAIL-induced apoptosis in different tumor cell types (Fig. 6). By contrast, $\mathrm{KCl}$ and U37883A, another type of $\mathrm{K}_{\mathrm{ATP}}$ inhibitor, which also caused persistent PMD $(52,53)$, enhanced nonapoptotic cell death all cell types tested. These observations indicate that persistent PMD can promote non-apoptotic cell death, as well as canonical apoptosis. Since the enhancement of the two modes of cell death was proceeded by mitochondrial network aberration (Fig. 7), these findings suggest that the mitochondrial network aberration leads to different modes of cell death.

It is noteworthy that PSM was more potent than TRAIL in disrupting the $\mathrm{Ca}^{2+}$ dynamics. PSM increased both $\left[\mathrm{Ca}^{2+}\right]_{\text {cyt }}$ and $\left[\mathrm{Ca}^{2+}\right]_{\text {mit }}$ levels (Fig. 8), and persistent PMD could mimic the effect of the latter, but not the former (Fig. 9), suggesting that distinct $\mathrm{Ca}^{2+}$ entry pathways with different sensitivities to PMD may contribute to these $\mathrm{Ca}^{2+}$ responses. PSM seemed to increase the ER $\mathrm{Ca}^{2+}$ stores in cancer cells, thereby compromising SOCE, as SOCE is activated in response to $\mathrm{Ca}^{2+}$ depletion in the stores. Since persistent PMD can also lead to SOCE inactivation (Fig. 8), PSM may elicit the effect through PMD. An increasing body of evidence suggests that SOCE plays a pivotal role in malignant phenotypes, including the evasion of cell death (59). Thus, the inactivation of SOCE may play a role in the antitumor activity of the PSM. Given that is a critical regulator of the mitochondrial network dynamics in these cancer cells $(46,47)$, the effects may also contribute to the mitochondrial network aberration. Further analyses of the mechanisms underlying $\mathrm{Ca}^{2+}$ dynamics modulation by the PSM are ongoing.

In conclusion, in this study, and to the best of our knowledge, we demonstrate for the first time that the PSM has a significant advantage over TRAIL in killing TRAIL-resistant cancer cells from different origins owing to its capacity to evoke a $\mathrm{Ca}^{2+}$-dependent, caspase-independent cell death. The findings may provide fundamentals for the development of PSM as a novel approach for the treatment of TRAIL-resistant cancer cells.

\section{Acknowledgements}

The authors would like to thank the Health Science Research Resource Bank (Osaka, Japan), Riken BioResource Center, and Dr Eugenie Kleinerman for providing the cell lines. This study was supported in part by JSPS KAKENHI grant nos. 16K10851 to T.A., $15 \mathrm{~K} 09792$ to T.O., $15 \mathrm{~K} 06883$ to M.S. and $15 \mathrm{~K} 09750$ to Y.S.-K.

\section{Competing interests}

The authors declare that they have no competing interests.

\section{References}

1. Cerchia $\mathrm{C}$ and Lavecchia A: Small molecule drugs and targeted therapy for melanoma: Current atrategies and future directions. Curr Med Chem 24: 2312-2344, 2017.

2. Kalal BS, Upadhya D and Pai VR: Chemotherapy resistance mechanisms in advanced skin cancer. Oncol Rev 11: 326 , 2017.
3. Li S, Sun W, Wang H, Zuo D, Hua Y and Cai Z: Research progress on the multidrug resistance mechanisms of osteosarcoma chemotherapy and reversal. Tumour Biol 36: 1329-1338, 2015.

4. He H, Ni J and Huang J: Molecular mechanisms of chemoresistance in osteosarcoma (Review). Oncol Lett 7: 1352-1362, 2014.

5. Almasan A and Ashkenazi A: Apo2L/TRAIL: Apoptosis signaling, biology, and potential for cancer therapy. Cytokine Growth Factor Rev 14: 337-348, 2003

6. Johnstone RW, Frew AJ and Smyth MJ: The TRAIL apoptotic pathway in cancer onset, progression and therapy. Nat Rev Cancer 8: 782-798, 2008.

7. Wang S: The promise of cancer therapeutics targeting the TNF-related apoptosis-inducing ligand and TRAIL receptor pathway. Oncogene 27: 6207-6215, 2008.

8. Gonzalvez F and Ashkenazi A: New insights into apoptosis signaling by Apo2L/TRAIL. Oncogene 29: 4752-4765, 2010.

9. Kischkel FC, Lawrence DA, Chuntharapai A, Schow P, Kim KJ and Ashkenazi A: Apo2L/TRAIL-dependent recruitment of endogenous FADD and caspase- 8 to death receptors 4 and 5 . Immunity 12: 611-620, 2000.

10. LeBlanc HN and Ashkenazi A: Apo2L/TRAIL and its death and decoy receptors. Cell Death Differ 10: 66-75, 2003.

11. Ivanov VN, Bhoumik A and Ronai Z: Death receptors and melanoma resistance to apoptosis. Oncogene 22: 3152-3161, 2003.

12. Dyer MJ, MacFarlane M and Cohen GM: Barriers to effective TRAIL-targeted therapy of malignancy. J Clin Oncol 25: 4505-4506, 2007.

13. Dimberg LY, Anderson CK, Camidge R, Behbakht K, Thorburn A and Ford HL: On the TRAIL to successful cancer therapy? Predicting and counteracting resistance against TRAIL-based therapeutics. Oncogene 32: 1341-1350, 2013.

14. Guiho R, Biteau K, Heymann D and Redini F: TRAIL-based therapy in pediatric bone tumors: How to overcome resistance. Future Oncol 11: 535-542, 2015.

15. de Miguel D, Lemke J, Anel A, Walczak H and MartinezLostao L: Onto better TRAILs for cancer treatment. Cell Death Differ 23: 733-747, 2016.

16. Keidar M, Walk R, Shashurin A, Srinivasan P, Sandler A, Dasgupta S, Ravi R, Guerrero-Preston R and Trink B: Cold plasma selectivity and the possibility of a paradigm shift in cancer therapy. Br J Cancer 105: 1295-1301, 2011.

17. Zucker SN, Zirnheld J, Bagati A, DiSanto TM, Des Soye B, Wawrzyniak JA, Etemadi K, Nikiforov M and Berezney R: Preferential induction of apoptotic cell death in melanoma cells as compared with normal keratinocytes using a non-thermal plasma torch. Cancer Biol Ther 13: 1299-1306, 2012.

18. Ishaq M, Evans MM and Ostrikov KK: Effect of atmospheric gas plasmas on cancer cell signaling. Int J Cancer 134: 1517-1528, 2014.

19. Vandamme M, Robert E, Lerondel S, Sarron V, Ries D, Dozias S, Sobilo J, Gosset D, Kieda C, Legrain B, et al: ROS implication in a new antitumor strategy based on non-thermal plasma. Int $\mathrm{J}$ Cancer 130: 2185-2194, 2012.

20. Guerrero-Preston R, Ogawa T, Uemura M, Shumulinsky G, Valle BL, Pirini F, Ravi R, Sidransky D, Keidar M and Trink B: Cold atmospheric plasma treatment selectively targets head and neck squamous cell carcinoma cells. Int J Mol Med 34: 941-946, 2014.

21. Ishaq M, Kumar S, Varinli H, Han ZJ, Rider AE, Evans MD, Murphy AB and Ostrikov K: Atmospheric gas plasma-induced ROS production activates TNF-ASK1 pathway for the induction of melanoma cancer cell apoptosis. Mol Biol Cell 25: 1523-1531, 2014.

22. Hirst AM, Simms MS, Mann VM, Maitland NJ, O'Connell D and Frame FM: Low-temperature plasma treatment induces DNA damage leading to necrotic cell death in primary prostate epithelial cells. Br J Cancer 112: 1536-1545, 2015.

23. Wang M, Holmes B, Cheng X, Zhu W, Keidar M and Zhang LG: Cold atmospheric plasma for selectively ablating metastatic breast cancer cells. PLoS One 8: e73741, 2013.

24. Vandamme M, Robert E, Lerondel S, Sarron V, Ries D, Dozias S, Sobilo J, Gosset D, Kieda C, Legrain B, et al: ROS implication in a new antitumor strategy based on non-thermal plasma. Int $\mathrm{J}$ Cancer 130: 2185-2194, 2012.

25. Utsumi F, Kajiyama H, Nakamura K, Tanaka H, Mizuno M, Ishikawa K, Kondo H, Kano H, Hori M and Kikkawa F: Effect of indirect nonequilibrium atmospheric pressure plasma on antiproliferative activity against chronic chemo-resistant ovarian cancer cells in vitro and in vivo. PLoS One 8: e81576, 2013. 
26. Torii K, Yamada S, Nakamura K, Tanaka H, Kajiyama H, Tanahashi K, Iwata N, Kanda M, Kobayashi D, Tanaka C, et al: Effectiveness of plasma treatment on gastric cancer cells. Gastric Cancer 18: 635-643, 2015.

27. Hattori N, Yamada S, Torii K, Takeda S, Nakamura K, Tanaka H, Kajiyama H, Kanda M, Fujii T, Nakayama G, et al: Effectiveness of plasma treatment on pancreatic cancer cells. Int J Oncol 47: $1655-1662,2015$

28. Adachi T, Tanaka H, Nonomura S, Hara H, Kondo S and Hori M: Plasma-activated medium induces A549 cell injury via a spiral apoptotic cascade involving the mitochondrial-nuclear network. Free Radic Biol Med 79: 28-44, 2015

29. Kurake N, Tanaka H, Ishikawa K, Kondo T, Sekine M, Nakamura K, Kajiyama H, Kikkawa F, Mizuno M and Hori M: Cell survival of glioblastoma grown in medium containing hydrogen peroxide and/or nitrite, or in plasma-activated medium. Arch Biochem Biophys 605: 102-108, 2016.

30. Elustondo PA, Nichols M, Robertson GS and Pavlov EV: Mitochondrial $\mathrm{Ca}^{2+}$ uptake pathways. J Bioenerg Biomembr 49: 113-119, 2017.

31. Bonora M, Wieckowski MR, Chinopoulos C, Kepp O, Kroemer G, Galluzzi L and Pinton P: Molecular mechanisms of cell death: Central implication of ATP synthase in mitochondrial permeability transition. Oncogene 34: 1475-1486, 2015.

32. Izzo V, Bravo-San Pedro JM, Sica V, Kroemer G and Galluzzi L: Mitochondrial permeability transition: New findings and persisting uncertainties. Trends Cell Biol 26: 655-667, 2016.

33. Galluzzi L, Bravo-San Pedro JM, Kepp O and Kroemer G: Regulated cell death and adaptive stress responses. Cell Mol Life Sci 73: 2405-2410, 2016.

34. Orrenius S, Gogvadze V and Zhivotovsky B: Calcium and mitochondria in the regulation of cell death. Biochem Biophys Res Commun 460: 72-81, 2015.

35. Danese A, Patergnani S, Bonora M, Wieckowski MR, Previati M, Giorgi $\mathrm{C}$ and Pinton P: Calcium regulates cell death in cancer: Roles of the mitochondria and mitochondria-associated membranes (MAMs). Biochim Biophys Acta 1858: 615-627, 2017.

36. Marchi S and Pinton P: Alterations of calcium homeostasis in cancer cells. Curr Opin Pharmacol 29: 1-6, 2016.

37. Monteith GR, Prevarskaya N and Roberts-Thomson SJ: The calcium-cancer signalling nexus. Nat Rev Cancer 17: 367-380, 2017.

38. Landes T and Martinou JC: Mitochondrial outer membrane permeabilization during apoptosis: The role of mitochondrial fission. Biochim Biophys Acta 1813: 540-545, 2011.

39. Elgass K, Pakay J, Ryan MT and Palmer CS: Recent advances into the understanding of mitochondrial fission. Biochim Biophys Acta 1833: 150-161, 2013.

40. Twig G and Shirihai OS: The interplay between mitochondrial dynamics and mitophagy. Antioxid Redox Signal 14: 1939-1951, 2011.

41. Chen H, Chomyn A and Chan DC: Disruption of fusion results in mitochondrial heterogeneity and dysfunction. J Biol Chem 280: 26185-26192, 2005.

42. Hoppins S, Lackner L and Nunnari J: The machines that divide and fuse mitochondria. Annu Rev Biochem 76: 751-780, 2007.

43. Akita M, Suzuki-Karasaki M, Fujiwara K, Nakagawa C, Soma M, Yoshida Y, Ochiai T, Tokuhashi Y and Suzuki-Karasaki Y: Mitochondrial division inhibitor-1 induces mitochondrial hyperfusion and sensitizes human cancer cells to TRAIL-induced apoptosis. Int J Oncol 45: 1901-1912, 2014.

44. Suzuki-Karasaki Y, Fujiwara K, Saito K, Suzuki-Karasaki M, Ochiai T and Soma M: Distinct effects of TRAIL on the mitochondrial network in human cancer cells and normal cells: Role of plasma membrane depolarization. Oncotarget 6: 21572-21588, 2015.
45. Saito K, Asai T, Fujiwara K, Sahara J, Koguchi H, Fukuda N, Suzuki-Karasaki M, Soma M and Suzuki-Karasaki Y: Tumorselective mitochondrial network collapse induced by atmospheric gas plasma-activated medium. Oncotarget 7: 19910-19927, 2016.

46. Takata N, Ohshima Y, Suzuki-Karasaki M, Yoshida Y, Tokuhashi Y and Suzuki-Karasaki Y: Mitochondrial $\mathrm{Ca}^{2+}$ removal amplifies TRAIL cytotoxicity toward apoptosis-resistant tumor cells via promotion of multiple cell death modalities. Int J Oncol 51: 193-203, 2017.

47. Ohshima Y, Takata N, Suzuki-Karasaki M, Yoshida Y, Tokuhashi Y and Suzuki-Karasaki Y: Disrupting mitochondrial $\mathrm{Ca}^{2+}$ homeostasis causes tumor-selective TRAIL sensitization through mitochondrial network abnormalities. Int J Oncol 51: 1146-1158, 2017.

48. Judée F, Fongia C, Ducommun B, Yousfi M, Lobjois V and Merbahi N: Short and long time effects of low temperature Plasma Activated Media on 3D multicellular tumor spheroids. Sci Rep 6: 21421, 2016.

49. Utsumi F, Kajiyama H, Nakamura K, Tanaka H, Mizuno M, Toyokuni S, Hori M and Kikkawa F: Variable susceptibility of ovarian cancer cells to non-thermal plasma-activated medium. Oncol Rep 35: 3169-3177, 2016.

50. Adachi T, Kano A, Nonomura S, Kamiya T and Hara H: Histone deacetylase inhibitors stimulate the susceptibility of A549 cells to a plasma-activated medium treatment. Arch Biochem Biophys 606: 120-127, 2016.

51. Kurake N, Tanaka H, Ishikawa K, Kondo T, Sekine M, Nakamura K, Kajiyama H, Kikkawa F, Mizuno M and Hori M: Cell survival of glioblastoma grown in medium containing hydrogen peroxide and/or nitrite, or in plasma-activated medium. Arch Biochem Biophys 605: 102-108, 2016.

52. Suzuki Y, Inoue T, Murai M, Suzuki-Karasaki M, Ochiai T and $\mathrm{Ra}$ C: Depolarization potentiates TRAIL-induced apoptosis in human melanoma cells: Role for ATP-sensitive $\mathrm{K}^{+}$channels and endoplasmic reticulum stress. Int J Oncol 41: 465-475, 2012.

53. Suzuki-Karasaki M, Ochiai T and Suzuki-Karasaki Y: Crosstalk between mitochondrial ROS and depolarization in the potentiation of TRAIL-induced apoptosis in human tumor cells. Int $\mathrm{J}$ Oncol 44: 616-628, 2014.

54. McCarthy JV and Cotter TG: Cell shrinkage and apoptosis: A role for potassium and sodium ion efflux. Cell Death Differ 4: 756-770, 1997.

55. Lang F, Föller M, Lang K, Lang P, Ritter M, Vereninov A, Szabo I, Huber SM and Gulbins E: Cell volume regulatory ion channels in cell proliferation and cell death. Methods Enzymol 428: 209-225, 2007.

56. Bortner CD, Gomez-Angelats $\mathrm{M}$ and Cidlowski JA: Plasma membrane depolarization without repolarization is an early molecular event in anti-Fas-induced apoptosis. J Biol Chem 276: 4304-4314, 2001

57. Nolte F, Friedrich O, Rojewski M, Fink RH, Schrezenmeier H and Körper S: Depolarisation of the plasma membrane in the arsenic trioxide (As2O3)-and anti-CD95-induced apoptosis in myeloid cells. FEBS Lett 578: 85-89, 2004.

58. Yin W, Li X, Feng S, Cheng W, Tang B, Shi YL and Hua ZC: Plasma membrane depolarization and Na,K-ATPase impairment induced by mitochondrial toxins augment leukemia cell apoptosis via a novel mitochondrial amplification mechanism. Biochem Pharmacol 78: 191-202, 2009.

59. Jardin I and Rosado JA: STIM and calcium channel complexes in cancer. Biochim Biophys Acta 1863: 1418-1426, 2016.

(i) $\ominus$ This work is licensed under a Creative Commons Attribution-NonCommercial-NoDerivatives 4.0 International (CC BY-NC-ND 4.0) License. 